\title{
The World Production and Trade of Rare Earth Elements: The Position of the Pacific Area*
}

\author{
Carlos Encinas-Ferrer, Francisco Javier Valderrey-Villar \\ Tecnologico de Monterrey Campus Leon, Leon, Mexico \\ Clemente Hernandez-Rodriguez \\ Tecnologico de Monterrey Campus Guadalajara, Guadalajara, Mexico \\ Antonio Uson-Sardaña \\ Universidad de Zaragoza, Zaragoza, España
}

\begin{abstract}
In this paper we analyze the characteristics of the so-called rare earth elements (REEs) and its industrial applications. We present the policy, or lack thereof, in the countries in the Pacific Rim for its mining and commerce, and the current and future weight that rare earth minerals will have in international trade. The technological revolution experienced over the last 25 years, has brought the REEs to the public's attention for being instrumental in obtaining catalysts, lasers and optical fiber, luminescent substances and LEDs, superconductors, permanent magnets, batteries and ultra-capacitors. China's leading position as the supplier of these minerals worldwide, and its recent export restriction policy for domestic industrial activities have driven up international prices. Price increase for REEs is leading to the need for both recycling and its replacement. It has also led other countries in the Asia Pacific Rim to prospect new potential sites on their own territories, or even to restart operations in deposits that had been previously abandoned. Those strategies will likely gain greater importance as environmental pollution problems associated with the exploitation, processing, and recovery of REEs increase.
\end{abstract}

Keywords: rare earth metals or elements, China, REEs production, trade, public policies, prospecting, technological revolution

\section{Introduction}

The term rare earth element (REE) referring to oxides of the 17 elements of the periodic table with atomic number 57 to 71, known as lanthanides, plus scandium (21), and yttrium (39) - has been applied to some metals in the belief that they are scarce, special, thin, rare or raw. However, these metals are not scarce, but they can commonly be found mixed with other elements.

\footnotetext{
* Project Supported: Research Group "Production, Use and Global Trade of Rare Earth Elements" of the Tecnologico de Monterrey (ITESM) Campus Leon.

Carlos Encinas-Ferrer, Ph.D., in Economics, Tecnologico de Monterrey Campus Leon.

Clemente Hernandez-Rodriguez, Ph.D. in Economics, Asia Pacific Center, Tecnologico de Monterrey Campus Guadalajara.

Antonio Uson-Sardaña, Ph.D. in Electrical Engineering, Department of Electrical Engineering, School of Engineering and Architecture, Universidad de Zaragoza.

Francisco Javier Valderrey-Villar, Ph.D. in Administration and Marketing, Tecnologico de Monterrey Campus Leon.

Correspondence concerning this article should be addressed to Clemente Hernandez-Rodriguez, Av. General Ramon Corona 2514, Col. Nuevo Mexico. Zapopan, Jalisco, 45201, Mexico. E-mail: clemente.hernandez@itesm.mx.
} 
The issue of rare earth elements (REEs) production serves as an example of the problems that have arisen with the export boom in China and the transnational companies' desire to obtain relatively cheap labor and take advantage of lax environmental rules. While rare earths minerals, with the exception of promethium, are not considered per se radioactive, they are usually found alongside other radioactive elements, increasing the risk of pollution at the sites of exploitation.

The Chinese authorities, aware of the importance of these minerals for technological development in key industries, were cautious to plan in advance its exploration and exploitation in bulk. Prices dropped to such minimum levels that the rest of the world discontinued production in fields already in operation, which caused its subsequent abandonment, such as it happened in the U.S.

Recently, however, China has reduced its export quotas of REEs, which in turn has caused an increase in the prices of these commodities. The reasons for this embargo are many and diverse and therefore will be the subject of further work by our research group. Given this reduction in export quotas applied by China, the U.S., Japan and some European nations have expressed their concerns, even to the point of initiating legal actions at the World Trade Organization (WTO) to ensure the supply of these strategic minerals. Moreover, several countries have started their own exploitation and export activities, and many others have initiated exploration for those elements in their own territories.

The market for these elements has grown dramatically in recent years because of its multiple applications in the manufacturing of goods in the electronic, computing, or renewable energy industries. In this first paper, we provide a detailed explanation of the features of these minerals, as well as a historical sketch of the evolution that the production of these elements has had in recent years, which are key to the technological and computing revolution.

We found at the beginning of our work that a significant amount of investment in research and development $(\mathrm{R} \& \mathrm{D})$ in the coming years could lead to the generation of new technologies, mainly addressing the following three areas: greater efficiency in the use of materials, substitutes or alternatives to rare earths elements, and recycling of rare earth elements. Those areas will be instrumental in our future work, but so will be the environmental aspect, since recent history of exploitation and recycling of these elements has been accompanied by a surge in pollution.

\section{Features of the REEs}

The REEs are known since 1794, when the Finnish chemist J. Gadolin found in the mines of Ytterby (near Stockholm, Sweden) a mineral (oxide of a hitherto unknown element) which he called yttria. Throughout the 19 th century new minerals were discovered corresponding to oxides of elements whose atomic numbers (number of elementary negative electrical charges, electrons surrounding the nucleus of the atom) were between 57 and 71. Weeks (1932) recounts the discovery of these elements, which include scientists like J. C. G. Marignac, C. Auer, P. T. Cleve and G. Urbain. The last of the elements was discovered for the atomic number 61, recognized among the fission products of uranium in 1947 (Babor \& Aznárez, 1979). In the periodic table, these elements are lanthanum, atomic number 57, so they are also known as lanthanides. Lanthanides together with lanthanum and yttrium (atomic number 39) constitute the 16 elements of the REEs. Usually the list also includes scandium (atomic number 21) as it belongs to the same group of the periodic table IIIB as lanthanum and yttrium table. Table 1 presents the elements belonging to the REEs, its symbol, atomic number, and electronic configuration. 
Table 1

Lanthanides or Rare Earth Elements

\begin{tabular}{llll}
\hline Element & Symbol & Atomic Number & Electronic configuration \\
\hline scandium & $\mathrm{Sc}$ & 21 & {$[\mathrm{Ar}] 4 s^{2} 3 d^{1}$} \\
yttrium & $\mathrm{Y}$ & 39 & {$[\mathrm{Kr}] 5 s^{2} 4 d^{1}$} \\
lanthanum & $\mathrm{La}$ & 57 & {$[\mathrm{Xe}] 6 s^{2} 5 d^{1}$} \\
cerium & $\mathrm{Ce}$ & 58 & {$[\mathrm{Xe}] 4 f^{1} 6 s^{2} 5 d^{1}$} \\
praseodymium & $\mathrm{Pr}$ & 59 & {$[\mathrm{Xe}] 4 f^{3} 6 s^{2}$} \\
neodymium & $\mathrm{Nd}$ & 60 & {$[\mathrm{Xe}] 4 f^{4} 6 s^{2}$} \\
promethium & $\mathrm{Pm}$ & 61 & {$[\mathrm{Xe}] 4 f^{5} 6 s^{2}$} \\
samarium & $\mathrm{Sm}$ & 62 & {$[\mathrm{Xe}] 4 f^{6} 6 s^{2}$} \\
europium & $\mathrm{Eu}$ & 63 & {$[\mathrm{Xe}] 4 f^{7} 6 s^{2}$} \\
gadolinium & $\mathrm{Gd}$ & 64 & {$[\mathrm{Xe}] 4 f^{7} 6 s^{2} 5 d^{1}$} \\
terbium & $\mathrm{Tb}$ & 65 & {$[\mathrm{Xe}] 4 f^{9} 6 s^{2}$} \\
dysprosium & $\mathrm{Dy}$ & 66 & {$[\mathrm{Xe}] 4 f^{10} 6 s^{2}$} \\
holmium & $\mathrm{Ho}$ & 67 & {$[\mathrm{Xe}] 4 f^{11} 6 s^{2}$} \\
erbium & $\mathrm{Er}$ & 68 & {$[\mathrm{Xe}] 4 f^{12} 6 s^{2}$} \\
thulium & $\mathrm{Tm}$ & 69 & {$[\mathrm{Xe}] 4 f^{13} 6 s^{2}$} \\
ytterbium & $\mathrm{Yb}$ & 70 & {$[\mathrm{Xe}] 4 f^{14} 6 s^{2}$} \\
lutetium & $\mathrm{Lu}$ & 71 & {$[\mathrm{Xe}] 4 f^{14} 6 s^{2} 5 d^{1}$} \\
\hline
\end{tabular}

The REEs are active metals (elements with a tendency to lose electrons to form positive ions, usually trivalent) which are attached directly to the oxygen and nitrogen. The atomic structure differs only in the number of electrons in the $4 f$ band (empty for $\mathrm{La}$ and full for $\mathrm{Lu}$ ), which just involved in chemical bonds, which causes that all these elements chemically behave similarly. The three electrons outside the structure of xenon $[\mathrm{Xe}]$ (common to all elements) are responsible for their metallic behavior in the solid state. The electrons that partially occupy the $4 f$ band are responsible for their specific magnetic properties (Rhyne \& McGuire, 1972).

The REEs color is associated to its trivalent ions which are capable of absorbing radiation of a determined wavelength of visible light. This wavelength corresponds to the energy requiring for an electron to pass through the higher energy level, which in turn depends on the number of unpaired electrons in the $4 f$ band. Table 2 lists the lanthanide ions color.

These elements are very difficult to separate from the mineral in which they are combined, and for it methods such as fractional crystallization, fractional precipitation, solvent extraction and ion exchange are used (Petrucci, Herring, Madura, \& Bissonnette, 2011).

Cerium is the most abundant of these elements and has been the most widely used. It forms part of the pyrophoric alloy Mischmetal $(50 \% \mathrm{Ce}, 40 \% \mathrm{La}, 7 \% \mathrm{Fe}, 3 \%$ other metals) traditionally used in lighters, in incandescent muffs for gas lighting, in the manufacture of glass, hydrocarbon catalysis and as additive in steel to improve its strength (Babor \& Aznárez, 1979; Lee, 1991).

The main industrial applications of REE are: catalysts, lasers, and optical fiber, luminescent substances and LEDs, superconductors, permanent magnets, batteries and ultra-capacitors. Those applications are explained below. 
Table 2

Lanthanide Ions Color

\begin{tabular}{lll}
\hline Ion & $4 f$ electrons & Color \\
\hline $\mathrm{La}^{3+} \mathrm{Ce}$ & 0 & Colorless \\
$\mathrm{Ce}^{3+}$ & 1 & Colorless \\
$\mathrm{Pr}^{3+}$ & 2 & Green \\
$\mathrm{Nd}^{3+}$ & 3 & Violet \\
$\mathrm{Pm}^{3+}$ & 4 & Pink \\
$\mathrm{Sm}^{3+}$ & 5 & Yellow \\
$\mathrm{Eu}^{3+}$ & 6 & Pale pink \\
$\mathrm{Gd}^{3+}$ & 7 & Colorless \\
$\mathrm{Tb}^{3+}$ & 8 & Pale pink \\
$\mathrm{Dy}^{3+}$ & 9 & Yellow \\
$\mathrm{Ho}^{3+}$ & 10 & Pale yellow \\
$\mathrm{Er}^{3+}$ & 11 & Pink \\
$\mathrm{Tm}^{3+}$ & 12 & Pale green \\
$\mathrm{Yb}^{3+}$ & 13 & Colorless \\
$\mathrm{Lu}^{3+}$ & 14 & Colorless \\
\hline
\end{tabular}

\section{Catalysis}

Substances that remain unchanged accelerate with their presence the velocity of chemical reactions. The cerium oxides are used in automotive catalytic converters. They store oxygen that subsequently is used to convert carbon monoxide $(\mathrm{CO})$ to carbon dioxide $\left(\mathrm{CO}_{2}\right)$ by the following chemical reactions:

$$
\begin{gathered}
2 \mathrm{Ce}_{2} \mathrm{O}_{3}+\mathrm{O}_{2} \rightarrow 4 \mathrm{CeO}_{2} \\
2 \mathrm{CeO}_{2}+\mathrm{CO} \rightarrow \mathrm{Ce}_{2} \mathrm{O}_{3}+\mathrm{CO}_{2}
\end{gathered}
$$

Cerium oxides are also used in oil refineries. In 1997, the U.S. consumed about 19,400 t of REEs, being $48 \%$ used in automobile catalytic converters and $17 \%$ in the oil industry (Housecroft \& Sharpe, 2001).

\section{Lasers and Optical Fiber}

The discoveries of the laser (light amplification by stimulated emission of radiation) together with fiber optics have led to considerable progress in data transmission and telecommunications. This system uses coherent light emitted by the laser and confined in the optical fiber to transmit large volumes of data (thousands of gigabits of information per second) with little loss in signal amplitude, and also little vulnerability to interference. The laser also has important applications in medicine (diagnosis, ophthalmology, dermatology, cosmetic surgery, etc.).

Some elements of the REEs are essential for manufacturing some of the most widespread lasers. The neodymium laser was discovered by Wallace and Harris (1969) and is constituted by a rod of YAG (Ytrium Aluminiun Garnet, $\mathrm{Y}_{3} \mathrm{Al}_{5} \mathrm{O}_{12}$ ) containing a low concentration of $\mathrm{Nd}^{3+}$ that normally emits in the infrared band, with a wavelength around $1064 \mathrm{~nm}$, although with techniques for frequency doubling you can get to emit at 532 $\mathrm{nm}$. The YAG is also used in jewelry as an imitation of diamond and other precious stones.

Another key element in the communication through the optical fiber was the discovery of the amplifier of fiber doped with erbium (EDFA) and ytterbium (Digonnet, 2001; P. Martín, J. Martín, \& Chamorro, 2010). The importance of the EDFA is its ability to amplify signals of wavelength from $1530 \mathrm{~nm}$ to $1560 \mathrm{~nm}$ (1.53 to 1.56 
$\mu \mathrm{m})$ which are transmitted over conventional optical fiber with very low loss. These fibers have allowed the propagation of a signal of $2.5 \mathrm{~Gb} / \mathrm{s}$ (gigabits per second) over 21,000 km. Employing 274 erbium amplifiers, separated an average distance of $33 \mathrm{~km}$, AT\&T and KDD companies managed to spread a signal of $5 \mathrm{~Gb} / \mathrm{s}$ over $9,000 \mathrm{~km}$. The optical fiber can be improved by doping with erbium and ytterbium; pumping with light of 980 $\mathrm{nm}$ we get an efficient excitation of ytterbium ions to be transferred to the erbium ions.

The use of praseodymium as a dopant in the core of a ZBLAN fiber (mixture of fluorides of zirconium, barium, lanthanum, aluminum and sodium) allowed the development of the first signal amplifier of wavelength of $1.3 \mu \mathrm{m}$ (mid-infrared), known as $2 \mathrm{nd}$ window, and to which the losses in the fiber are lower than those in optical signals with shorter wavelengths.

\section{Luminescent Substances and LEDs}

The REEs have been used for making luminescent substances (light emitting) since the mid-19th century. Scientist Crookes (1883) cited and analyzed the phosphorescent emissions of yttrium and some other REEs. They were not used to produce phosphorescent substances until late 1950, with the discovery of the laser (Buchanan \& Wickersheim, 1968). Currently this property is the reason of REEs performances of flat screens FPD (flat panel displays), of some of the light emitting diode (LED—Light Emitting Diode) and fluorescent energy saving light bulbs.

Luminescent phosphors based on REEs emit red, green and blue, primary colors from which the required color range for color screens is obtained. In the devices known as TFEL (Thin Film Electroluminescence), the green color is obtained by $\mathrm{ZnSTb}^{3+}$ nanocrystals, $\mathrm{SrSCe}^{3+}$ nanocrystals are used for blue and $\mathrm{CaSEu}^{2+}$ and $\mathrm{ZnSSm}^{3+}$ crystals are used for red. The white crystals can be obtained with $\mathrm{SrSCe}^{3+}, \mathrm{Eu}^{2+}$, and $\mathrm{SrSPr}^{3+}$ crystals (Leskelä \& Niinistö, 1992; Kim et al., 2000).

The high-efficiency LED diodes that emit white light with very low electric energy consumption, use REEs in some cases. Its rapid development is allowing them to be a competitive alternative to conventional tungsten bulbs and fluorescent energy saving light bulbs. To manufacture these new light sources materials such as the Ce-doped YAG, luminescent phosphors such as BOSE (barium orthosilicate) and TAG $\left(\mathrm{Tb}_{3} \mathrm{Al}_{5} \mathrm{O}_{12}\right)$ doped with $\mathrm{Ce}, \mathrm{Eu}$, and $\mathrm{Tb}$ are used. Also nitrides of gallium, indium and aluminum doped with REEs to improve their performance may be used for this purpose ( $\mathrm{Li}, 2005)$.

Another important application is in medicine when used as biological tracers in drugs, to be readily detected in the human body by spectroscopy (Lee, 1991).

\section{Superconductors}

The phenomenon of superconductivity was discovered in 1911 by Kamerlingh-Onnes. It involves the disappearance of the resistance of metals to the passage of an electric current. The resulting effect of the electrical resistance is the generation heat (Joule loss effect) causing a decrease in the performance of electrical machines, power transmission systems, and high magnetic field generation devices such as the electromagnets used in medical devices for clinical diagnostics. Superconductivity occurs at very low temperatures, close to absolute zero $\left(0 \mathrm{~K}=273.15^{\circ} \mathrm{C}\right)$, which precludes its widespread use in electrical engineering. Throughout the 20th century investigators have been trying to obtain materials that exhibit superconductivity at higher temperatures. A fundamental step in the development of superconducting materials took place in 1987, when it was observed that ceramic materials consisting of lanthanum, strontium, copper and oxygen behave as superconductors at temperatures higher than $30 \mathrm{~K}\left(-243{ }^{\circ} \mathrm{C}\right)$. One such material is known as $\mathrm{YBCO}$ 
$\left(\mathrm{YBa}_{2} \mathrm{Cu}_{3} \mathrm{O}_{7}\right)$, which is easily obtained by heating a mixture of yttrium oxide $\left(\mathrm{Y}_{2} \mathrm{O}_{3}\right)$, barium carbonate $\left(\mathrm{BaCO}_{3}\right)$ and copper oxide II $(\mathrm{CuO})$ in the presence of a stream of oxygen $\left(\mathrm{O}_{2}\right)$. It behaves as a superconductor at temperatures below $92 \mathrm{~K}\left(-181{ }^{\circ} \mathrm{C}\right)$, allowing to cool it with liquid nitrogen, an inexpensive liquid that is $77 \mathrm{~K}$ $\left(-196{ }^{\circ} \mathrm{C}\right)$. Variations can be made of YBCO formula replacing yttrium with any lanthanide (especially dysprosium) and barium with combinations of elements from Group 2. All these items belong to the second generation of high-temperature superconductors, known by the acronym 2G HTS (Petrucci et al., 2011; Long et al., 2005).

YBCO along with superconductors based on magnesium diboride $\left(\mathrm{MgB}_{2}\right)$ and bismuth oxide-strontium-calcium-copper (BSCCO) will mean in 2017 a market of 370 million dollars, compared with 12.3 million dollars in 2012. The most important technological application of these components in the short term, even bigger than the manufacture of superconductor electrical cables, is in current limiters for the protection of electrical equipment (SFCL = superconductive fault current limiters) (BCC Research, 2012; Schmidt et al., 2010; Kudymow, Elschner, Maeder, \& Goldacker, 2011).

\section{Permanent Magnets}

Permanent magnets have been instrumental in the development of electrical and electronic applications from the beginning of electrical engineering. They have been used in a variety of applications, from building small dynamos and alternators to the magnetrons microwave ovens. Until the incorporation of REEs in manufacturing permanent magnets, iron alloys with aluminum, nickel and cobalt, known as Alnico, and the iron oxides with hexagonal structure known as ferrites, have been the most used materials for the manufacture of permanent magnets. Ferrite magnets developed by Went and colleagues at the Philips Laboratories, have a better magnetic behavior than those of Alnico, but are more fragile (Cochardt, 1966). Today, they are still the most used.

In 1966 K. J. Stmat and colleagues from the materials laboratory of the U.S. Air Force found that REEs alloys with cobalt showed strong magnetic anisotropy (Magnet Energy Corp, 1974). The first permanent magnet based on this property was developed with samarium, SmCo5. In 1972 K. J. Stmat and A. Ray improved their properties by adding $\mathrm{Fe}, \mathrm{Cu}$, and $\mathrm{Zr}$ to an alloy of $\mathrm{Sm}_{2} \mathrm{Co}_{17}$.

In 1982, Sagawa together with its partners in the Sumitomo Special Metals Company obtained the first magnet sintered from Neodymium-Iron-Boron, Nd-Fe-B, which exceeded the magnetic properties of the magnet $\mathrm{Sm}_{2} \mathrm{Co}_{17}$. To improve its heat resistance in some alloys, part of the $\mathrm{Nd}$ was substituted by Dy. The production of these magnets in 2012 surpassed the 90,000 t/year (Sagawa et al., 1984; Sagawa, 2012). Also in 1982, Croat obtained in the research laboratories of General Motors magnets of Nd-Fe-B through a casting process (Croat, Herbst, Lee, \& Pinkerton, 1984). In 2012 the production of this type of magnets was estimated at 8,000 t/year.

The most common application for this type of magnets is the manufacture of electronic devices, particularly hard drives for computers. But they are also vital in the manufacture of special electrical machines, since they improve performance and reliability of motors and generators. In the automotive industry, the electric motors of hybrid cars incorporate permanent magnets, as their traction characteristics are better suited to this application. They are also incorporated in the magnetic circuit of synchronous generators installed in large wind turbines (Barcaro, Bianchi, \& Magnussen, 2009).

\section{Batteries and Ultra-capacitors}

Also parallel to the development of electric motors through REEs magnets, and because of the potential 
for development of electric vehicles and systems for power generation with renewable energy, it has been perfected systems for storing electrical energy in the form of batteries or capacitors. The REEs appear in NiMh battery anodes and they begin to appear in ultracapacitors electrodes in the form of nickel oxide (NMRO-Mesopore Nickel-based Rare-earth oxide) and of graphene (PPy/graphene nanosheets) (Liu et al., 2006; Sunb \& Moa, 2013).

\section{World Production and Reserves}

Until 2011, the U.S. had abandoned the operation of its large reservoir of Mountain Pass. But in 2012, the U.S. is returning to be a producer, and the same thing happened in Australia in 2011.

What about Mexico? Given the geological similarities of the northwest region of Mexico with de deposit of Mountain Pass in the southwestern U.S., the existence of large deposits in our country is viable (Hernández-Rodríguez, 2013), but its exploitation faces constitutional legal issues that need to be addressed in subsequent research.

Table 3 shows the changes in the global production of these minerals since 2000. It emphasizes the dominant share of China in its production, but also the emergence of Brazil in 2004 and Australia in 2011 as exporters. It shows also the reincorporation of the U.S. as producer.

Table 3

Rare Earth Elements: Estimated Mining Production by Country (Metric Tons Oxides Equivalent)

\begin{tabular}{llllllll}
\hline Year & Australia & Brazil & China & India & Malaysia & U.S.A. & Total \\
\hline 2000 & - & - & 73,000 & 2,700 & 446 & - & 92,700 \\
2001 & - & - & 80,600 & 2,700 & 351 & - & 89,500 \\
2002 & - & - & 88,000 & 2,700 & 240 & - & 93,000 \\
2003 & - & - & 92,000 & 2,700 & 360 & - & 97,100 \\
2004 & - & 402 & 98,000 & 2,700 & 800 & - & 102,000 \\
2005 & - & 527 & 119,000 & 2,700 & 150 & - & 122,000 \\
2006 & - & 527 & 133,000 & 2,700 & 430 & - & 137,000 \\
2007 & - & 645 & 120,000 & 2,700 & 380 & - & 124,000 \\
2008 & - & 550 & 125,000 & 2,700 & 380 & - & 129,000 \\
2007 & - & 645 & 120,000 & 2,700 & 380 & - & 124,000 \\
2008 & - & 460 & 125,000 & 2,700 & 120 & - & 128,000 \\
2009 & - & 170 & 129,000 & 2,700 & 13 & - & 132,000 \\
2010 & - & 140 & 120,000 & 2,800 & 310 & - & 123,000 \\
2011 & 2,188 & 140 & 105,000 & 2,800 & 280 & - & 110,000 \\
2012 & 4,000 & 300 & 95,000 & 2,800 & 350 & 7,000 & 109,450 \\
\hline
\end{tabular}

Note. Source: Based on data from U.S. Geological Survey, Mineral Commodity Summaries 2000 and 2013.

In Table 4 we present 2011 and 2012 figures for production and estimated reserves, as percentages over total 2012 output or reserves of the main countries. It is evident the decline in reserves in China when taken as a percentages of the total global reserves, in spite of the fact that only three years ago Chinese reserves accounted for more than $70 \%$ of the world total.

It is clear, as noted above, that the estimates of world reserves will change substantially in the coming years. Most probably, we will see a sharp increase in the figures shown in Table 4. Recent price increases in world prices for these minerals, will represent an incentive to many countries to carry out exploration and 
drilling, increasing, thus, global supply. For the moment, as previously mentioned, the U.S. has reactivated the exploitation of Mountain Pass and reserves of this field are becoming important again.

Table 4

World Production and Reserves 2011-2012

\begin{tabular}{|c|c|c|c|c|c|c|}
\hline \multirow{2}{*}{ Countries } & \multicolumn{4}{|c|}{ Mining production } & \multirow{2}{*}{-Estimated reserves } & \multirow{2}{*}{$\%$ of reserves } \\
\hline & 2011 & $\%$ & 2012 & $\%$ & & \\
\hline U.S.A. & - & $0.0 \%$ & 7,000 & $6.3 \%$ & $13,000,000$ & $11.8 \%$ \\
\hline Australia & 2,200 & $2.0 \%$ & 4,000 & $3.6 \%$ & $1,600,000$ & $1.5 \%$ \\
\hline Brazil & 250 & $0.2 \%$ & 300 & $0.3 \%$ & 36,000 & $0.0 \%$ \\
\hline China & 105,000 & $95.0 \%$ & 95,000 & $85.9 \%$ & $55,000,000$ & $50.0 \%$ \\
\hline India & 2,800 & $2.5 \%$ & 2,800 & $2.5 \%$ & $3,100,000$ & $2.8 \%$ \\
\hline Malaysia & 280 & $0.3 \%$ & 350 & $0.3 \%$ & 30,000 & $0.0 \%$ \\
\hline Other Countries & NA & NA & NA & NA & $41,000,000$ & $37.3 \%$ \\
\hline World Total & 110,530 & $100.0 \%$ & 110,530 & $100.0 \%$ & $110,000,000$ & $100.0 \%$ \\
\hline
\end{tabular}

Notes. Source: Based on data from the USGS (2013).

In Figure 1 China's dominant position in world production and trade of REEs is fully evident. Since 1985, China has obtained a significant participation in global production, causing a fast process of production decline in the U.S. and other countries, due to the low prices of Chinese production. Starting in 2003, U.S. production ceased at all, being only reactivated by 2012, with an approximate output of 7,000 metric tons.

We can divide the history of the world production of REEs into three stages. The first stage, between 1956 and 1965, was named Monazite-placer, referring to the placer mining of monazite and other rare earth minerals and thorium found in the southeastern U.S.. The second one, ranging from 1965 to 1985, was named the Mountain Pass era, while the third one, ranging from 1985 to date, was named the Chinese era. During this last stage, the Chinese era, the fall of production in the U.S. and the rest of the world can only be explained by extremely low prices in Chinese production, from either legal or illegal exploitations in China.

In 2010, China imposed quotas and other restraints to sharply limit exports of REEs. Given that most of nine-tenths of the world production of REEs occurred in China, price shock hit foreign producers who relied on Chinese minerals.

It seems like the export restraints, China ruled, were designed to achieve industrial policy goals rather than promote conservation. That is, China sought to limit its exports of REEs to give a leg up to Chinese manufacturers and also sought to use cheaper domestic prices to entice foreign companies dependent on REEs to relocate production to China. The strategy worked with large gains. Chinese manufacturers in several industries relying on REEs, such as wind turbines and chemicals, made formidable inroads against their foreign competitors. Foreign companies making products relying on REEs, such as camera lenses and touchscreen glass, outsourced or shifted production to China (Wu, 2014).

Japan, the European Union and the US filed complaints before the World Trade Organization (WTO) that the export restraints were discriminatory and illegal, inconsistent with WTO rules. China defended its actions by arguing that the export limits were necessary because of the environmental hazards associated with REEs production. At the end of March 2014 a WTO panel ruled that China's export restraints on REEs and other metals were discriminatory, thus China needs to dismantle those discriminatory practices. As a result of the WTO ruling it is very likely that China will lift export tariffs. 


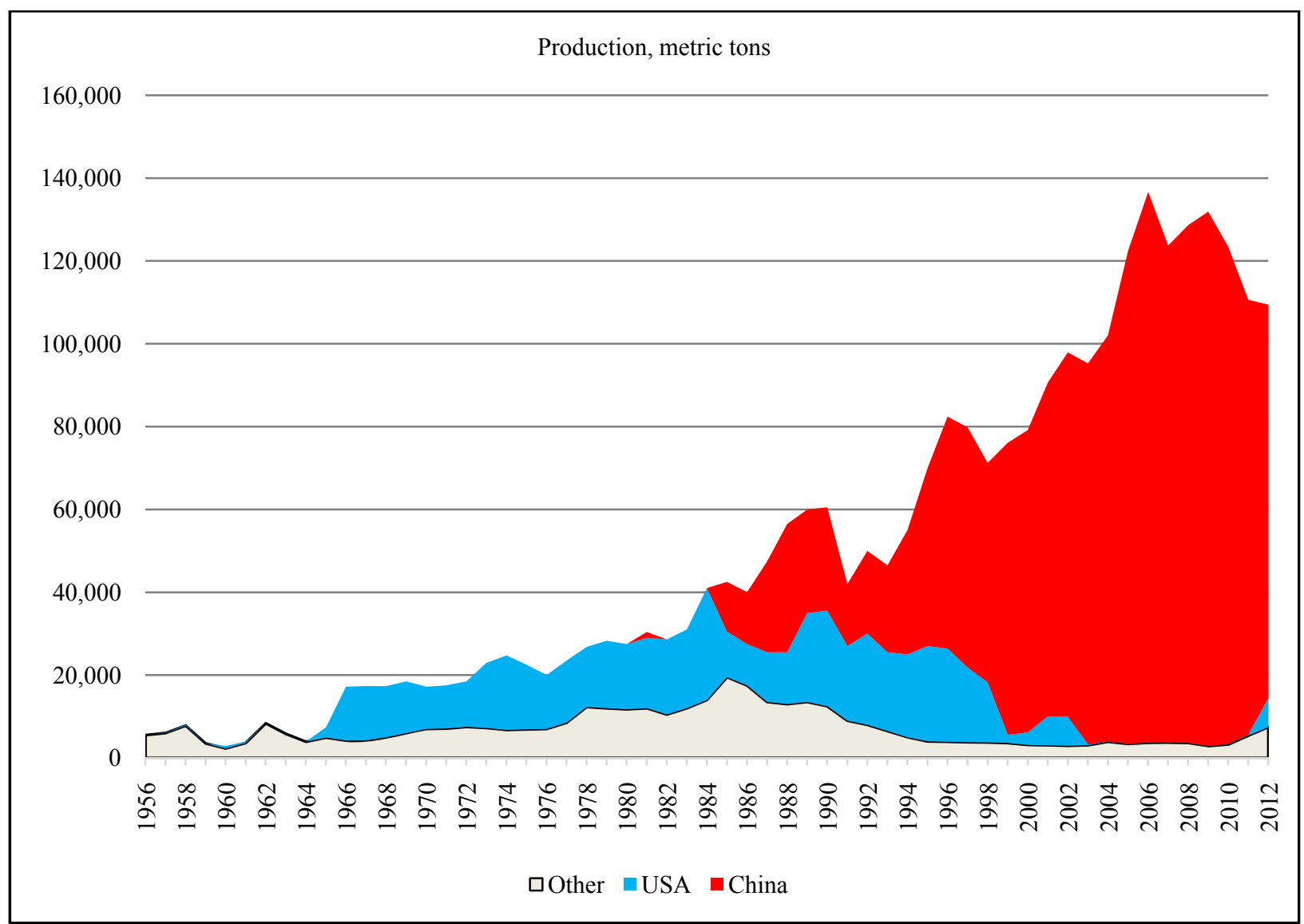

Figure 1. Global trend in production of rare earth oxides. Source: Updated from USGS (2013). USA. Graph from Cordier (USA Geological Survey, written commun. 2011).

Next strategy is to impose taxes by Chinese ministries on the value of the rare earth minerals which will increase rare earth prices. Presently taxes are imposed on volume. That shift will mean higher prices at the producer level and reflects the scarcity of these resources and the environmental cost of their extraction (Wang, 2014). Higher prices will change the supply-demand equilibrium, undercut the smuggling trade and reduce high inventories of REEs in other countries.

After analyzing the trade balance of REEs in the U.S., it becomes surprising that the fact that during the years 2003 to 2011, U.S. figures account for an average volume of 8,000 metric tons in exports, even though there was no local production. In the statistics from the U.S. Geological Survey (USGS, 2013), the import category is reported as imports for consumption; therefore, it can be assumed that the U.S. has acted as an intermediary, importing to further export those minerals to other countries, as it may be seen in Figure 2.

In Figure 3, American exports and annual production of REEs are shown, making thus clearer that between 2003 and 2011, production ceased in U.S. but its export's position remained basically unchanged. In 2012, production exceeds exports again, with a decline in the amount of metric tons imported from 7,791 in 2011 to 5,654 in 2012. We note that in 2000 the amount of metric tons imported was 23,868 with an estimated value of about $\$ 216$ million dollars. 


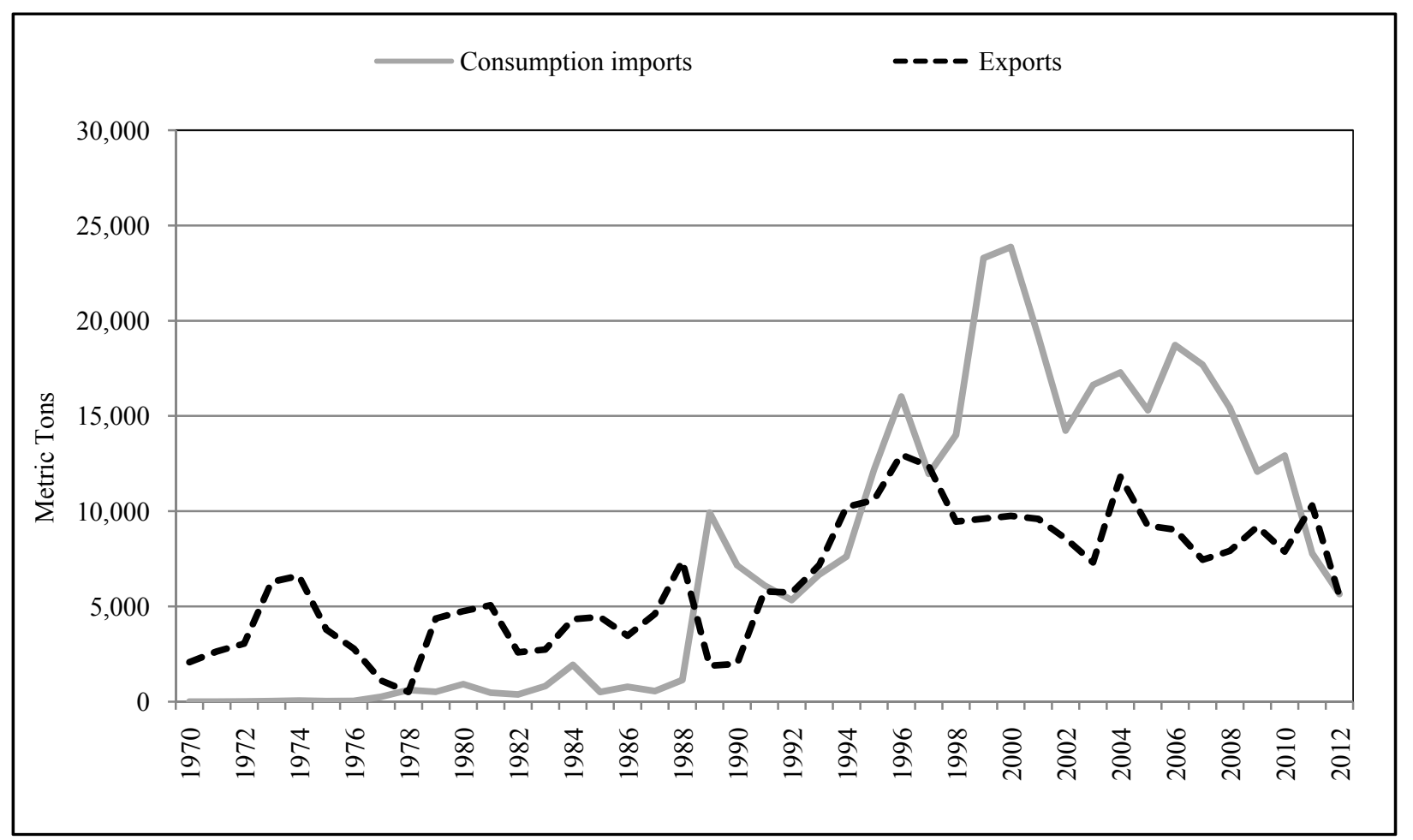

Figure 2. Consumption imports and exports of REEs in the USA. Source: Based on data from the USGS (2013).

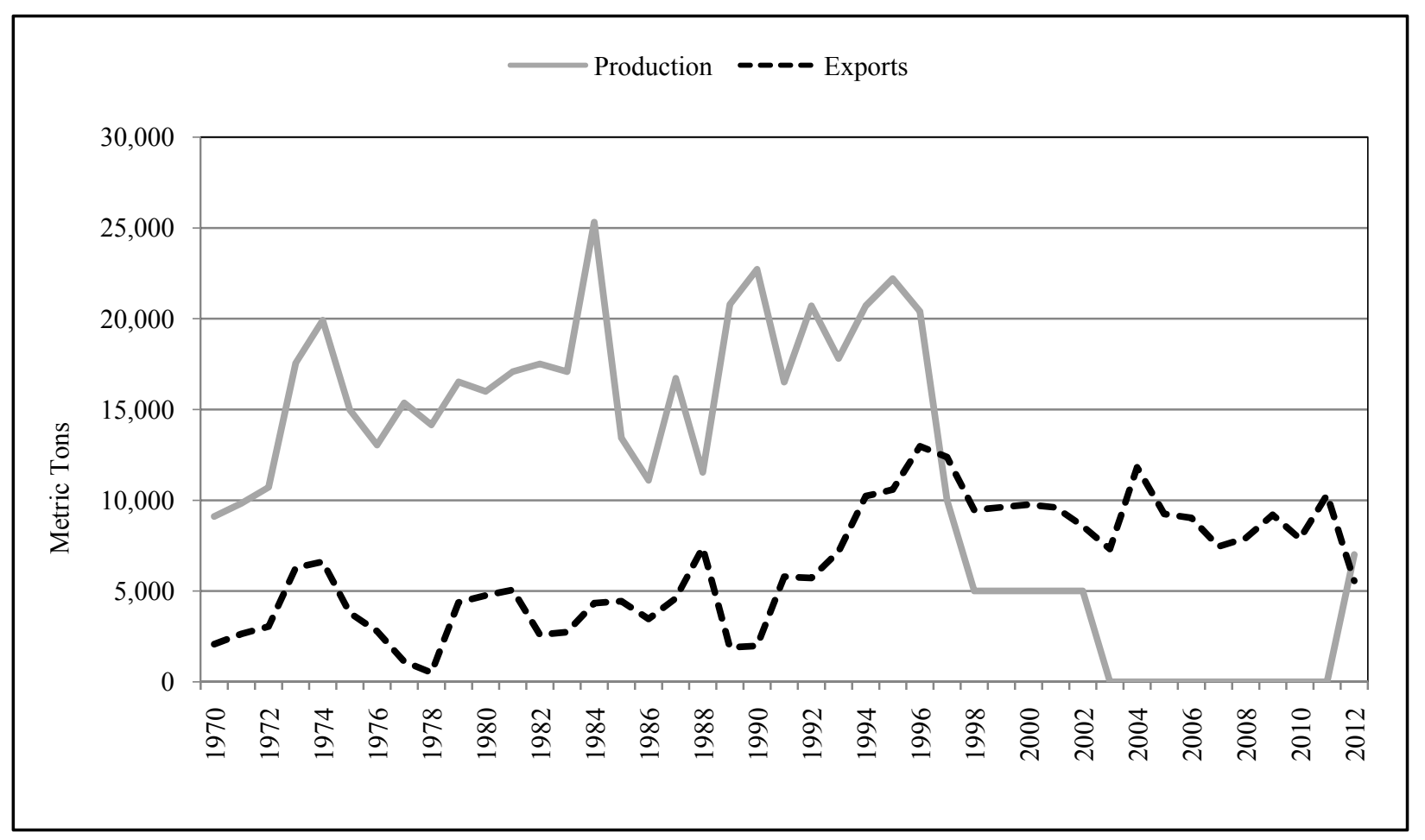

Figure 3. USA: Production and exports. Source: Based on data from the USGS (2013). 


\section{Recycling}

Price increase for REEs is leading to the need for both recycling and its replacement by more conventional and cheaper materials. This is the case of the ferrite magnets which replace the Nd-Fe-B engine (Petrov \& Pyrhönen, 2013) and permanent magnet generators, electric motors and switched reluctance, replacing the electric traction motors with permanent magnets (Pietrelli, Bellomo, Fontana, \& Montereali, 2002).

Recycling of fluorescent energy-saving lamps can help to recover some of the TTRR used in their manufacture (such as described by Wang, Mei, Zhao, \& Lei, 2011). At present only $1 \%$ of REEs are recycled but it is estimated that $20 \%$ of global demand could be supplied through reuse (Binnemans, 2013), which puts the recycling of rare earths as an economic activity with a great future.

\section{Conclusions}

In this paper, we showed the physical and chemical characteristics of the rare earths elements and their participation in the development of new technologies and, therefore, its future importance. We also presented an overview of the evolution of global production for those elements, for the past 13 years, which allowed us to conclude that in the coming years it is foreseeable a substantial change in the number of producing countries, as well as in their own respective output figures and estimated reserves. Re-establishing robust domestic supply chains for such rare earth minerals is needed to reduce the US foreign mineral dependency. Stockpiles should be built to guard against attempts to use REEs as economic leverage. Those changes will probably gain greater importance as environmental pollution problems associated with the exploitation, processing, and recovery of REEs increase.

Our research group will, therefore, focus on those issues and will be monitoring the evolution and geographical distribution of the production of REEs. Technological applications are evolving quickly, and are closely related to the advancements in the technical issues related to the rare earth elements. Rare earth minerals are critical in a wide range of industries, from electronic and hybrid automobiles to petroleum and chemicals all of them of strategic interest. The research topic, thus, acquires substantial importance when looking at the future of some strategic industries. Scholarly research for REEs is consequently ample and complex, certainly beyond our initial expectations.

\section{References}

Babor, J. A., \& Aznárez, J. I. (1979). Modern general chemistry (Química general moderna) (8th ed.). Barcelona: Editorial Marín. Barcaro, M., Bianchi, N., \& Magnussen, F. (2009). PM motors for hybrid electric vehicles. The Open Fuels \& Energy Sci. J. 2, 135-141.

BCC Research. (2012). Superconductors: Technologies and global markets. Retrieved from http://www.bccresearch.com/market-research/advanced-materials/superconductors-technologies-applications-markets-avm06 6c.html

Binnemans, K. (2013). Recycling rare earth elements using ionic liquids. Retrieved December 19, 2013, from http://www.rsc.org/chemistryworld/2013/03/recycling-rare-earth-neodymium-and-samarium-ionic-liquids

Buchanan, R. A., \& Wickersheim, K. A. (1968). Rare earth phosphors and scintillators. IEEE Transactions on Nuclear Science, 15(3), 95-101.

Cochardt, A. (1966). Recent ferrite magnet developments. J. Appl. Phys. 37, 1112.

Croat, J. J., Herbst, J. F., Lee, R. W., \& Pinkerton, F. E. (1984). High energy product NdFeB permanent magnets. Appl. Phys. Lett. $44,148$.

Crookes, W. (1883). On radiant matter spectroscopy: The detection and wide distribution of Yttrium Phil. Trans. R. Soc. Lond, $174,891-918$. 
Digonnet, M. J. F. (2001). Rare earth doped fiber lasers and amplifiers (2nd ed.). New York: Marcel Dekker.

Hernández-Rodríguez, C. (2013). Las relaciones entre China y Latinoamérica en la década de los 2010. In J. I. Martínez (Ed.), América Latina y El Caribe-China Relaciones Políticas e Internacionales (pp. 121-137). Mexico City: UNAM Red ALC-China UDUAL.

Housecroft, C. E., \& Sharpe, A. G. (2001). Inorganic chemistry (1st ed.). Harlow, Essex: Pearson Education.

Kim, C. H., Kwon, I. E., Park, C. H., Hwang, Y. J., Bae, H. S., Yu, B. Y., ... Hong, G. Y. (2000). Phosphors for plasma display panels. Journal of Alloys and Compounds, 311, 33-39.

Kudymow, A., Elschner, S., Maeder, O., \& Goldacker, W. (2011). Optimization of 2G YBCO wires for resistive fault current limiters. IEEE Trans. Applied Superconductivity, 21(3), 1311-1314.

Lee, J. D. (1991). Concise inorganic chemistry (4th ed.). London: Chapman \& Hall.

Leskelä, M., \& Niinistö, L. (1992). Applications of rare earths in full-colour EL displays. Materials Chemistry and Physics, 31(1-2), 7-11.

Li, Y. Q. (2005). Structure and luminescence properties of novel rare-earth doped silicon nitride based materials. Retrieved December 19, 2013, from http://alexandria.tue.nl/extra2/200512598.pdf

Liu, H., He, P., Li, Z., Liu, Y., \& Li, J. (2006). A novel nickel-based rare-earth oxide/activated carbon supercapacitor using room temperature ionic liquid electrolyte. Electrochimica Acta, 51(10), 1925-1931.

Long, N., Strickland, N., Chapman, B., Ross, N., Xia, J., Li, X., ...Rupich, M. (2005). Enhanced in-field critical currents of YBCO second-generation (2G) wire by Dy additions. Supercond. Sci. Technol, 18, S405.

Magnet Energy Corp. (1974). History of rare earth magnets. Retrieved January 16, 2014, from http://www.magnetnrg.com/repm-history.html

Martín, P., Martín, J., \& Chamorro, P. (2010). Amplificadores de fibra óptica dopada con Erbio e Iterbio. Retrieved December 19, 2013 , http://es.scribd.com/doc/33388581/Amplificadores-de-fibra-optica-dopada-con-Erbio-e-Iterbio-EDFAs-y-YEDFAs

Petrov, I., \& Pyrhönen, J. (2013). Performance of low cost permanent magnet material in PM synchronous machines. IEEE Trans. on Industrial Electronics, 60(6), 2131-2138.

Petrucci, R. H., Herring, F. G., Madura, J. D., \& Bissonnette, C. (2011). Química general (10th ed.). Madrid: Pearson Educación.

Pietrelli, L., Bellomo, B., Fontana, D., \& Montereali, M. R. (2002). Rare earths recovery from NiMH spent batteries. Hydrometallurgy, 66(1-3), 135-139.

Rhyne, J. J., \& McGuire, T. R. (1972). Magnetism of rare-earth elements, alloys, and componds. IEEE Trans. on Magn., 8, $105-130$.

Sagawa, M. (2012). How the world's strongest “Neodymiun Magnet” came to exist. Retrieved December 19, 2013, from http://www.japanprize.jp/data/prize/commemorative_lec_2012_e.pdf\#page=13\&view=Fit

Sagawa, M. Sumitomo Special Metals Company, Fujimura, S., Yamamoto, H., Matsuura, Y., \& Hiraga, K. (1984). Permanent magnet materials based on the rare earth-iron-boron tetragonal compounds. IEEE Trans. Mag., 20(5), 1584-1589.

Schmidt, W., Gamble, B., Kraemer, H. P., Madura, D., Otto, A., \& Romanosky, W. (2010). Design and test of current limiting modules $\quad$ YBCO-coated $\quad$ conductors. Retrieved from http://iopscience.iop.org/0953-2048/23/1/014024/pdf/0953-2048_23_1_014024.pdf

Sunb, W., \& Moa, Z. (2013). PPy/graphene nanosheets/rare earth ions: A new composite electrode material for supercapacitor. Material Science and Engineering B., 178, 527-532.

USGS. (2013). U.S. geological survey. Retrieved December 19, 2013, from http://www.usgs.gov/

Wallace, R. W., \& Harris, S. E. (1969). Oscillation and Doubling of the 0.946-m Line in $\mathrm{Nd}^{3+}$ : YAG. Appl. Phys. Lett., 15(4), 111-113.

Wang, M. (2014). Tax changes “will drive up rare earth prices”. Retrieved May 22, 2014, from http://www.chinadaily.com.cn/

Wang, X., Mei, G., Zhao, C., \& Lei, Y. (2011). Recovery of rare earths from spent fluorescent lamps. Proceedings from 5th International Conference on Bioinformatics and Biomedical Engineering (iCBBE) (pp. 1-4).

Weeks, M. E. (1932). The discovery of the elements: The rare earth elements. J. Chem. Educ, 9(10), 1751-1773.

Wu, M. (2014). A free pass for China. Retrieved April 4, 2014, from http://www.nytimes.com/ 